\title{
EL CUARTO HOMBRE
}

Alejandro Saavedra, $s d b$

Universidad Politécnica Salesiana (Ecuador)

Miembro de la Pontificia Academia Romana de Filosofía (Roma)

Es indiscutible el negar que asistimos a la afirmación de un "nuevo tipo" de hombre y que esto es un hecho que se acentúa cada vez más. Parecería que la exaltación del "superhombre" de Nietzsche, ${ }^{1}$ en cuanto a sus connotaciones, se delinean en una especie de hombre que se centra más en aquello que no es y no debe ser, que en lo que es en realidad. Podríamos afirmar que, por un lado, algo del hombre ha desaparecido y, por otro lado, algo vislumbramos de lo que está surgiendo sin saber con precisión. Intentemos penetrar en este intrincado camino histórico y del pensamiento para poder comprender el verdadero alcance del cuarto hombre que, representa un desafío no solamente a la educación, sino a la búsqueda seria de propuestas educativas que pretendan enraizarse en la cultura de hoy. ${ }^{2}$

\section{El devenir histórico del problema}

El primer hombre es el sujeto de la racionalidad aristotélica que busca su esencia para contradistinguirse de los demás seres del mundo. En efecto, la definición clásica de Aristóteles sobre el hombre "animal racional", ${ }^{3}$ resulta muy insuficiente, pues, "animal" nos hace pensar más al campo de la zoología y "racional" deviene muy limitado para comprender lo que es el hombre. La búsque- 
da de una definición estrictamente lógica no satisface a una reflexión antropológica.

Bajo esta influencia, Boecio llega a definir la persona como "sustancia racional de naturaleza individual". 4 Esta definición que ha sido repetida a lo largo de la historia como una de las más exitosas, fue puesta en crisis por el personalismo porque no permitía entender la integridad de la persona. ${ }^{5}$

A ello hay que agregar que la mentalidad griega de concebir el cosmos perfectamente ordenado y en el cual el hombre se somete a las leyes de la naturaleza, permite llegar a una incomprensión de la libertad humana para desembocar, más bien, en el eterno retorno de lo idéntico. ${ }^{6}$

El segundo hombre es el hombre de la fe, surgido por el aporte decisivo del Evangelio. Se trata de la revelación judeo-cristiana, en la que el hombre se reconoce como "imagen semejantísima de Dios" y como "hijo de Dios". 7 No es simplemente el esfuerzo racional del hombre, sino la iniciativa de Dios que descubre la verdad sobre el hombre.

Aquí debemos distinguir claramente lo que es la "filosofía de Cristo", es decir, el modo de pensar, de vivir, de comportarse de Jesucristo, y, la "filosofía sobre Cristo", es decir, la reflexión teológica que se hace sobre Jesucristo y que requiere de un sustento filosófico, tal como lo fue para San Agustín, San León Magno y otros. Digo esto, porque no podemos ignorar que la irrupción de la "filosofía de Cristo" no haya producido un cambio radical en el pensamiento greco-romano, tales como son los temas de la libertad humana, el rol de la mujer en la sociedad, la dignidad de la persona humana, el sentido de la muerte, etc. ${ }^{8}$

Este segundo hombre tiende en su vida "hacia un más allá” el cual encuentra, superando los límites del tiempo y del espacio. La eternidad, concepto que entró en 
la historia con Jesucristo, le permite mirar "más allá” de la historia. Por otro lado, se establece una relación armónica entre "fe" y "razón", entre "historia" y "metahistoria".9

El tercer hombre es el hombre moderno, burgués y calculador. Con este hombre se rompe la armonía entre fe y razón desde la misma reflexión filosófica. Descartes será un punto de referencia obligatorio al respecto, pues, lleva a arrinconar a la fe solamente "para ganar el cielo" sin mayor incidencia para la concreción histórica de su existencia. ${ }^{10}$ Se dará la espalda al saber religioso y se privilegiará el saber científico. La ciencia se convierte en instrumento tecnológico para el dominio del mundo y la religión como comportamiento ético que acompaña la realización del "Beruf" en el trabajo. ${ }^{11}$

Se trata del burgués que promueve el mito del progreso ("a mayor ciencia, mayor progreso y, a mayor progreso, mayor desarrollo de la humanidad), 12 la Providencia se laiciza hasta llegar a una "religión laical" y el conocimiento científico se convierte en el máximo estadio del desarrollo de la humanidad. ${ }^{13}$ Desembocamos en el hombre moderno que no es moderno en cuánto la modernidad es moderna a la edad clásica-medieval, sino en que considera lo "moderno" como un valor. Este carácter de lo "moderno" alcanza su cumbre con el "Aufhebung" de Hegel en el sentido de superar que incluye un doble contenido: destruir y conservar. ${ }^{14}$ Precisamente, la agonía de este tercer hombre llega por el mismo, por la radicalidad de su "abstracción" distanciada de la realidad existencial humana y por la impotencia de tocar preguntas existenciales. Es la rebelión de Kierkegaard al plantear la vuelta al cíngulo individuo, a la existencia humana concreta. ${ }^{15}$

Con la progresiva disolución del tercer hombre, ante la catástrofe de las dos guerras mundiales y ante la incapacidad de humanizar al hombre desde la "razón", ha na- 
cido el cuarto hombre, el de la época postmoderna, víctima del deseo y no de la necesidad, con tremenda indiferencia religiosa, sometido al devenir del cambio en la historia y sin ansia de verdad. ${ }^{16}$ Este hombre busca realizarse con sus propios instrumentos tecnológicos y sus propios "mass media", en los cuales, ciencia y magia llegan a coincidir. ${ }^{17}$

Lo que más se ha debilitado en este hombre es la historia: la tradición no interesa y el futuro ya terminó porque todo lo que venga después no es sino un sistema eterno del hacer y del consumar, con la ideología constante de lo nuevo como lo mejor. El progreso ha terminado, pues, hemos llegado a un historicismo absoluto que convierte el progreso en puro progreso sin sentido y sin finalidad. ${ }^{18}$ Se ve claramente la imposibilidad de "algo" que sea más allá, porque todo lo que viene como otro es, a la vez, necesario e inútil, al interior de un sistema que dado por terminado a la trascendencia.

Esta época postmoderna ha señalada el fin de la "utopía" por la misma necesidad e intranscendentabilidad de la utopía.

Vivimos, por consiguiente, en una época sin historia, en donde el presente se ha instalado en el inmediatismo y el presentismo. No puede haber un futuro entendido como algo "nuevo". Después, del período caótico teológico y después del período genético metafísico, la humanidad entró en el período "final" (científico), en la visión positivista; $\mathrm{y}$, ahora, ha entrado en el período posthistórico. Ahora, es posible el "suceder", el "acontecer" (Geschehen), pero no la historia (Geschichte).19

\section{El surgimiento del cuarto hombre}

El surgimiento del cuarto hombre está señalado por el paso de las tecnologías de las necesidades a las tecnologías de los deseos. En efecto, el tercer hombre confe- 
saba una confianza plena en el progreso y en la tecnología, en cuanto empieza a derrotar ciertos malestares del primer y del segundo hombre: las enfermedades, necesidades, situaciones de incomprensión ante ciertos mitos. En cambio, el cuarto hombre no busca solamente satisfacer sino trata de inventar nuevos deseos. ${ }^{20}$ La tecnología adecuada a esta inquietud es aquella que ofrecen los medios audiovisuales, los cuales, no son sino medios sustrayéndose a la necesidad y a la finalidad, desembocando en el placer sin interés y en la finalidad sin fin. ${ }^{21}$

Se pierde, por tanto, el "sentido histórico" de la relación entre los hechos y personajes, porque todos los acontecimientos son presentados de cualquier manera y en cualquier orden. Se produce una deshistorización del "medio" y se sobreponen el uno al otro. En referencia al tercer hombre, el cual, era histórico; el cuarto hombre es posthistórico en cuanto es postliterario y sus formas privilegiadas del saber son la experiencia y la expresión que se plasman sobre todo en el arte y en el juego. ${ }^{22} \mathrm{Si}$ tratamos de delinear los tipos de saber, podemos afirmar que, el cuarto hombre no privilegia el saber filosófico (primer hombre), ni el saber religioso (segundo hombre), ni el saber científico (tercer hombre), sino el saber estético que equivale al saber expresivo que encuentra en los mass-media, los instrumentos más eficaces.

Se trata de la sola fruición del bien de consumo y de la esteticidad como libre expresión y libre captación. La libre expresión, en cuanto no debe haber ningún límite a la capacidad expresiva que tiene el hombre, y, la libre captación del mundo, en cuanto cada uno se sitúa "a su modo" ante las circunstancias. Todo ello produce una especie de inconciliabilidad entre las expresiones y la captaciones. Adorno las había plasmado en su tajante afirmación: "castración de la percepción". ${ }^{23}$ Resulta casi imposi- 
ble llegar a consensos estables y firmes, puesto, que éstos, más bien, son efímeros y pasajeros. ${ }^{24}$ Marcel reconocía en ello un consenso momentáneo que llevaba al hombre a un compromiso con lo pasajero. ${ }^{25}$

De aquí se desprende que el cuarto hombre no vive en términos dramáticos la antítesis entre la verdad y la falsedad, de tal manera que ya no existen errores sino "errancias", en el doble sentido del verbo "errar": vagar y equivocarse. Por consiguiente, no se experimenta ninguna conflictualidad en las decisiones éticas. Se ven las decisiones del hombre, más bien, desde el punto de vista estético como "gusto" o como "placer". Lo que produce más gusto o placer. Surge un hombre que es más vagabundo en sus decisiones y que no se hace problemas éticos en sus elecciones.

Por otro lado, el haber dado la espalda al saber filosófico y al saber religioso, lleva a considerar algunos conceptos con "olor a naftalina", guardados y superados, tales como en el Dios, Ser, Verdad, etc., llegando a confundirse la historia con la fábula, el cuento con la realidad y la leyenda con la existencia. Estas confusiones llevan a un proceso de desubicación del hombre en su historia, llegando, incluso a banalizarla. ${ }^{26} 0$ Es así que en el mundo de los mass-media, la realidad se confunde con la fábula o el cuento, donde inclusive ni siquiera la fábula puede todavía existir. ${ }^{27}$ En este sentido, entendemos la multiplicación de los realities shows y talk show, en los cuales, la narración aparece como realidad histórica pero no lo es.

Por cuanto, respecta a la religión, el cuarto hombre no la rechaza, como tampoco objeta a la ciencia y a la filosofía; pero las considera como "juegos lingüísticos", en la consumación de un saber pluralístico y disipado. Se derrumba, por tanto, la búsqueda de una raciona- 
lidad universal, pretendida por el tercer hombre, para llegar a una racionalidad plural y divergente. No estamos, bajo el imperio de la lógica, si no de una lógica que llega a ser ilógica. ${ }^{28}$

Tenemos, así que el "hombre religioso" de hoy, no profesa demasiado a gusto verdades absolutas, sino que prefiere mantenerse en una religiosidad genérica e imprecisa, para llegar a un sincretismo entre las más dispares religiones. Puede darse que un católico recurra a ritos orientales budistas y los relacione con el Evangelio. Tenemos una "religión variopinta" al gusto del cliente que busca inventar nuevos deseos de "trascendencia". Casi se podría decir que no puede creer en modo real, sino a "un modo imaginativo" dependiente de sus deseos carentes, muchas veces, de un sustento racional. ${ }^{29}$

Surge una especie de hombre irónico porque sus palabras con las cuales se autodescribe están destinadas a cambiar ya que toma conciencia de la fragilidad de su vocabulario y de sí mismo. Por ende, nutre continuas dudas sobre sus palabras, sobre sus lecturas y sobre sus vocabularios que tienden a ser cada vez más cambiables; es consciente de que sus dudas no pueden ser resueltas por argumentos actuales; $y$, no tiene otra escapatoria que mezclar lo nuevo y lo viejo de sus palabras. Es como un "callejón sin salida" que le origina inseguridad e inestabilidad.

\section{El afirmarse del cuarto hombre}

Del saber estético que, hemos visto anteriormente, sobre el cuarto hombre se desprende su carácter individualístico ${ }^{30}$ con elementos muy peculiares: anárquico porque se somete a la libre expresión situacional de cada uno y por consiguiente imposible de comunicación, antiautoritario porque cualquier certeza aparece como 
dogmática y vertical y, posesivo porque más allá de lo que el "yo dice" resulta imposible ver y analizar. Se trata de una afirmación "radical" de la singularidad humana en cuanto individuo con tendencia a un "modo de pensar" negativo en cuanto busca aferrarse a negaciones: anti-clerical, anti-familiar, anti-militarista, etc. En el fondo del problema, está la radical espontaneidad individual expresiva como valor absoluto sin capacidad de confrontación con el otro. ${ }^{31}$ En el campo ético y educativo, podemos afirmar que constatamos el fracaso de ciertas campañas sobre valores radica en que, en vez, de proponer el valor, lanzan el anti-valor: "campaña contra la corrupción" y, no "campaña a favor de la honradez". Es el valor que me hace entender el anti-valor y, no viceversa.

Quisiéramos delinear algunos elementos fundamentales que constituyen este cuarto hombre para poder captar su carácter individual, estético y espontáneo.

\subsection{El cuarto hombre es un individuo y no una persona}

El corte radical y separación entre individuo y persona es evidente en el cuarto hombre. Indudablemente que ambos términos no son lo mismo, pero la separación tajante que hace el cuarto hombre es palpable y peligrosa para el hombre. La distinción conceptual no nos permite proceder a una neta división. En efecto, es individuo tanto un ladrillo como el hombre, pero es persona quien pertenece al mundo del espíritu. La persona es tal en fuerza de aquello que es y no de aquello que tiene y mucho menos en fuerza del reconocimiento que puede recibir de la sociedad y del otro.

Para los escolásticos, el individuo es el ente indiviso en sí mismo y diviso de otro ser. ${ }^{32}$ La indivisibilidad del individuo se afirma como incomunicabilidad e irrepe- 
tibilidad de su esencia individual y, por tanto, es totalmente en mismo y no en la parte de otro. Esto nos permite afirmar que, para los escolásticos el concepto de individuo tiene un carácter exquisitamente ontológico.

En la filosofía moderna, este concepto sufrió profundas transformaciones a partir del racionalismo que lo considera como sustancia pero con confusiones en torno al mismo término sustancia, desde Cartesio, del empirismo que lo considera como el conjunto de diversos estados fenoménicos de la conciencia y del liberalismo económico que lo hace destinatario del provecho económico sin referencia al bienestar social. Es interesante la concepción de Hegel que lo considera solamente como uno de los momentos dialécticos del Absoluto (=la Idea), perdiendo los individuos humanos y los diferentes pueblos su valor autónomo. Nietzsche llega a afirmar que el individuo posee un valor solamente en cuanto valor excepcional, es decir, en cuanto superhombre. ${ }^{33}$

En cambio, el concepto de persona indica reciprocidad, dialogicidad, comunicabilidad, cuyo origen reside en la reciprocidad y la relacionalidad de las personas de la Trinidad ${ }^{34}$, contrapuesto al de individuo, que indica singularidad y clausura en sí mismo. La persona es tal en cuanto tiene la potencialidad de la relación con el otro. La relación del "yo" con el "tú", empuja a la persona al encuentro y la sumerge en el dinamismo del diálogo. La verdadera relación interpersonal "yo-tú" no se agota en una forma de clausura y de egoísmo estéril, sino a partir de la riqueza de un "tú" conocido y amado, alarga y multiplica las relaciones interpersonales en la comunidad humana en la cual se encuentran inmersas. ${ }^{35}$ Esta relación "yo-tú" funda la búsqueda de la relación interpersonal fundamental con el Tú absoluto de Dios, fuente primordial del enriquecimiento del amor humano. ${ }^{36}$ 
Del paso del concepto de individuo al de persona, surge la necesidad de superar el atomismo de los individualismos mediante el diálogo y la comunicación para llegar a un personalismo, distante del individualismo y enraizado en una visión de la persona que es apertura, relación y comunicación. ${ }^{37}$ No podemos ignorar que la cultura actual que, muchos llaman "radical", no como corriente de pensamiento filosófico sino como mentalidad, actitud y comportamiento, propios de la sociedad postmoderna, rechaza el concepto de persona, porque es tildado de filosófico y teológico y, por tanto, "no científico". En el lenguaje científico al máximo se pretende aceptar el concepto de "individuo humano" y se le dá a esta formulación más que todo un contenido biológico, subrayando sin duda solamente el cuerpo. Indudablemente, el solo cuerpo no es todo el hombre. En el embrión como en el adulto el cuerpo no es todo el hombre. ${ }^{38}$

Para los defensores de la división tajante entre individuo y persona, el hombre es un individuo de la especie humana desde su concepción, pero sólo posteriormente llega a ser persona, cuando llega a tomar conciencia de sí mismo, a entrar en comunicación con los demás y es acogido por los otros. Profundizando podemos decir que, mientras en la filosofía clásica la división entre individuo y persona era solamente lógica y no ontológica porque toda persona es un individuo y todo individuo conlleva a ser persona; en la cultura radical actual, la división entre individuo y persona es ontológica, porque todo individuo no es una persona, y si no es una persona puede ser manipulado como un objeto cualquiera. Esta neta división trae como consecuencia, el hacer menos problemática determinados actos de la ciencia, como por ejemplo, la experimentación y el congelamiento de los embriones, porque si el embrión no es una persona sino "algo cosifi- 
cado", puede ser usado, por tanto, como objeto de experimentación y puede ser conservado y destruido, en un segundo momento.

De la concepción, del hombre como individuo y no como persona, deriva la cultura del individualismo que conlleva al egoísmo. ${ }^{39}$ Este individualismo se presenta, algunas veces, como un estilo de vida reservado y enclaustrado; otras veces, se encubre bajo el rostro de la raza, de la patria, de la familia, defendido contra otras patrias, familia y razas; otra veces, se profesa abiertamente como el derecho de los más fuertes; y, a veces, se presenta como un derecho conquistado por los conflictos sociales. Este individualismo egoísta está fuera y dentro de nosotros: forma parte de la dimensión animal y agresiva presente en el hombre, pero no se identifica con nuestra naturaleza humana, que se caracteriza sobre todo por la racionalidad y la relacionalidad.

Se llega a considerar al individuo como el único referente absoluto, en el cual, el yo es negación de todo el resto porque es absolutamente para sí mismo, es el "yo único", sin dejar espacio al otro. Nada hay sobre el yo y nada hay más allá de mi yo. ${ }^{40} \mathrm{El}$ "yo" de la antropología radical no tiene conciencia del otro porque todo otro es para él nada. ${ }^{41}$ Poniendo al otro como cosa, el "yo" deviene cosa a sí mismo, percibiéndose como realidad que hay que huir hacia el exterior, en la ignorancia de la pérdida de la propia esencia. El hombre postmoderno privilegia todo lo que es individual sobre todo aquello que es social. Es el sujeto único responsable de las decisiones de sus fines y de sus medios para realizar las aspiraciones de su vida.

De aquí se desprende que, al relacionarse con el otro no lo hace por razones de una común connaturalidad (los miembros interdependientes de la sociedad premoderna), ni por razones de una común ciudadanía (el 
ciudadano de la sociedad burgués-iluminista), y ni siquiera por razones de la común compañía (el compañero de la proyectualidad marxista). Lo hace únicamente en "clave" de interés. El otro entra en el cuadro de la propia vida en razón de que me es necesario para la realización de los fines que alcanzar y viceversa. Surge, así, la multiplicidad de intereses, padójicamente tantos, cuantas son las irreducibles individualidades. Postula inevitablemente, a un conjunto de "reglas de juego" indispensables para dirimir los nudos conflictuales, tratándose siempre de un conflicto de intereses. ${ }^{42}$

Una manifestación emblemática de cómo el hombre individualista se relaciona con los otros es la praxis del amor del hombre radical. En esta praxis, en cierto modo, no se aman personas, sino que se buscan placeres. La única vía que se recorre es la de la posesión, en la cual el interlocutor permanece un tanto mudo, sin llegar al reconocimiento, ni siquiera de sí mismo. En la negación de la naturaleza comunional de amor, la búsqueda del otro como compañero de placer no manifiesta nada, sino que más bien confirma la soledad y el replegamiento sobre sí mismo. Extrañándose a sí mismo, el sujeto permanece en una condición de ausencia de un sentido absoluto. ${ }^{43}$

En breve, en la cultura individualística encuentra particular acogida el dicho "tu muerte es mi vida", en el sentido que interés máximo es el propio bienestar, en desmedro de cualquier otro. En la perspectiva cristiana más auténtica, debería ser, "mi muerte es tu vida", es decir mi renuncia, mi sacrificio es aquello que permite la vida del otro. La palabra de orden del radicalismo es la posesión, aquélla del cristianismo, es la donación. ${ }^{44}$

Esto produce la existencia de una esperanza que no se refiere al cambio en el mundo, sino solamente a la 
propia existencia, al propio futuro personal, como fundamento de la búsqueda de gratificaciones individuales. Y, siendo producto de una cultura que ha arrinconado la tradición, se siente inseguro pero sin ser tentado de buscar seguridades en la experiencia del pasado porque éste le ha desencantado y desilusionado. De esta manera, exaspera la atención sobre sí mismo (primero "yo", segundo "yo" y tercero "yo"), la debilidad emotiva (es "bacán” lo que me causa emoción y sensación) y la autovulnerabilidad en la relaciones interpersonales. Lo individual prevalece sobre lo comunitario, cayendo en una especie de aislamiento y sensación de éxito individual "a toda costa" sin importar el grado de humanidad.

Llegamos a un individualismo radical caracterizado por la pluralidad de propuestas (multiplicación de propuestas individuales) y por el énfasis de una libertad individual que, muchas veces, llega a atropellar a la comunidad. Estamos en un bloqueamiento de la relación entre la persona, acentuada como individual, y la sociedad: indiferencia por el bienestar social, acentuamiento por el bien individual, choque de intereses individuales y perspectiva dispar sobre los valores. ${ }^{45}$ Se puede llegar, al máximo a un consenso pasajero pero no estable.

\subsection{El cuarto hombre es totalmente autónomo}

En la cultura postmoderna no existe un orden metafísico del ser y la inteligencia humana no está en grado de conocerlo. Y, si no hay un orden metafísico que fundamente una certeza de verdad, no puede haber tampoco una ley moral y una regla de los actos humanos, que pueda valer para todos. Por consiguiente, el sujeto actúa no por aquello que es bueno (=bien), sino por aquello que él desea o quiere. El sujeto se mueve en el ámbito de los deseos y no del bien. 
La conquista de la libertad hacia la cual tiende la praxis del hombre radical nos es la búsqueda de una liberación ética, de una plenitud de vida ética mediante la cual la persona se eleva interiormente en la virtud, en la sabiduría y en el amor. ${ }^{46}$ Se plantea, más bien, una libertad como satisfacción de los deseos, de las pasiones, garantizada por el pleno goce y placer. Estamos más en una espontaneidad de deseos sometidos a la imaginación que se constituye en la sede de la libertad. Tanto más se imagina, tanto más se expresa la libertad. Es un carácter estético que encuentra su raíz en la libre manifestación de los deseos sin ningún límite.

Por consiguiente, la libertad del individuo se expresa solamente como una forma de obediencia a sí mismo, y no acompañada por una responsabilidad hacia el bien común. Surge una asimetría entre la defensa de la absoluta autonomía individual con sus derechos y la indiferencia hacia los deberes que se tienen a los demás. Así tenemos, un creciente número de derechos sin sus correspondientes deberes. En ciertos planteamientos, los mismos derechos humanos carecen de fundamentación antropológica al privarse de una clara concepción del hombre. Nunca como hoy se han defendido los derechos humanos, nunca como hoy se ha hablado de la libertad humana, pero nunca como hoy hemos llegado casi a los límites de no saber "quién es el hombre", proyectando una defensa de la dignidad de la persona, muy débil y enclenque. ${ }^{47}$

Desde esta óptica, tampoco se puede justificar racionalmente la autoridad política y la obligación política porque el poder público solamente recibe significado desde el principio de utilidad. Así, la pregunta sobre la libertad política tiende a formularse más como búsqueda de libertad de la política, es decir del sentirse persona que 
participan en la vida de un pueblo, que se comunican entre ellas, cultural y proyectualmente.

La conquista de la libertad está orientada a un indefinido ejercicio de la libertad de elección y a la afirmación de una especie de libertad de independencia total. Desde este segundo punto de vista, la libertad se constituye como una libertad "de", que se puede presentar legítima como libertad de la pobreza, de la miseria, de la injusticia, pero que puede también ponerse, como búsqueda de la afirmación de una libertad del deber y de la responsabilidad, tal como se presenta frecuentemente. Se produce una desconexión de toda responsabilidad porque es considerada como un peso y no como un asumir el propio deber. ${ }^{48}$ En tal prospectiva, es urgente reconducir la libertad al crecimiento humano de la persona en cuanto está enraizada en la vida moral, racional y espiritual de la misma.

Resulta evidente que se introduce en el tejido de la vida social un principio que tiende a dar menos sentido a la responsabilidad y a ponerse ante los otros como realidades extrañas. La tendencia es considerar la libertad más como un bien ampliamente disponible y que la sociedad debe garantizar al hombre y no como una libertad plenamente humana. ${ }^{49}$

\subsection{El cuarto hombre es feliz por el placer y no por la virtud}

En la visión filosófica clásica la felicidad no consiste fundamentalmente en la posesión plena de la riqueza, en la buena fama, sino en el ejercicio constante de la virtud. El hombre feliz es aquél que vive conforme a la virtud y realizando en cada acto el desarrollo pleno de sus facultades humana: inteligencia y voluntad. De ahí que, Aristóteles afirma que la alegría acompaña a cada 
acto virtuoso. Y, la felicidad es una conquista de lo humano del hombre, y su real posibilidad reside en el hombre mismo, ${ }^{50}$ y es la fruición durable de los bienes que producen vida $y$, en tal sentido, se refiere a la vida humana entera en todos sus aspectos. El placer nace de la satisfacción de una necesidad y es como un primer grado hacia la felicidad, la cual es condición estable de la vida gozosa. Pero, el placer, respecto a la felicidad posee una limitada amplitud de goce.

En cambio, en la visión de la mentalidad radical, la felicidad consiste en la prolongación y el potenciamiento de toda forma de placer. Se trata de una especia de total liberación y satisfacción de los deseos, goce de la vida a toda costa, huida de toda forma de sufrimiento y ausencia de penas y de esfuerzo. Lo curioso que estos elementos convergen con la mentalidad consumística actual y la búsqueda del desencadenamiento de los deseos, solamente desde el punto de vista psíquico-biológico. En el sustrato hay una óptica antropológica que ahoga lo espiritual para dar paso a un hombre que no es solamente cuerpo sino también conducta. Dejamos, en claro que lo espiritual, en contraposición a esta propuesta para nada se separa de lo psíquico-biológico, sino que lo asume para darle un sentido pleno a la vida. ${ }^{51}$ En cambio bajo esta visión opuesta se derrumba la dimensión ética y espiritual de la felicidad, para quedar reducida a la sola dimensión sensible-psíquica que se manifiesta en el deseo o expresión libre de lo que desee.

Por consiguiente, el deseo se convierte en el único parámetro esencialmente real e inventor de la realidad. Se elimina así, todo lo que se constituye en norma y todo aquello que es estable, para sustituirlo por el deseo libre y sin fines, poniendo, así, en movimiento los "hombres que desean”. De este modo, apoderándose del goce y del pla- 
cer, éstos aparecerán como los únicos derechos a los que el hombre tiende ${ }^{52}$. En tales condiciones, se origina la muerte de la razón y surge la anarquía de los instintos. Contra la concepción del ser en términos del lógos, surge la concepción del ser en términos a-lógicos: voluntad y alegría, es decir, esta tendencia opuesta lucha por formular el propio lógos: la lógica de la satisfacción. ${ }^{53}$ Podríamos establecer la siguiente comparación: la necesidad es objetiva porque proviene de la naturaleza del hombre y responde a la realización del "quién" del hombre, mientras que el deseo es subjetivo porque varía según las condiciones sociales, económicas o culturales de quien lo puede expresar, y responde a la realización secundaria del "cómo" del hombre.

Recurriendo a otra comparación iluminante también podríamos decir que mientras el marxismo clásico proponía la teoría de las necesidades, el radicalismo del cuarto hombre propone la liberación de los deseos. En el primero, el hombre era liberado cuando sus necesidades eran satisfechas, en el segundo el hombre es liberado cuando da paso a la explosión de sus deseos que, a diferencia de la necesidad, no tiene un objeto predeterminado, sino que es insaciable, siempre nuevo. Podemos decir que se puede desear de todo, aún sin tener necesidad de nada. ${ }^{54}$

En el marco de una ética social este planteamiento ha traído enormes implicaciones, pues, se ha pasado de una cultura de los derechos del hombre a una cultura del hombre de los derechos, y el derecho que más reivindica es el del placer, entendido como la fuente y la base de la felicidad. El placer en la producción de la felicidad, ha sustituido a la virtud. La repercusión es tanto mayor puesto que todo placer posible y experimentable es legítimo, por el simple hecho de que pueda ser experimentado y no porque sea moralmente bueno. Uno se siente li- 
bre en la medida en logra satisfacer más deseos y éstos se satisfacen cuando se tiene de los medios y del dinero. El individuo, libre de las tradiciones y del eventual control social, procede a convertirse en "dios de sí mismo" y forma su realidad a la medida de sus propios deseos. ${ }^{55}$

$\mathrm{Al}$ respecto, podemos afirmar que mientras para el hombre moderno se trataba de satisfacer placeres, para el cuarto hombre (postmoderno) se trata de inventar y crear nuevos placeres. Esta creación de nuevos placeres no se apela para nada a la razón o a la lógica sino a la imaginación, a la capacidad imaginativa del hombre. Podemos entender, el surgir del nuevo tipo de discotecas en las grandes ciudades donde la combinación de distintos placeres están a la vista y paciencia de los asistentes. No hay límite a esta libre expresión y, cualquier intento de ponerlo suena a tradicionalismo, imposición autoritaria y pasado de moda. ${ }^{56}$ Estupendamente, lo ha señalado Amartya Sen, Premio Nobel de Economía 1998, cuando hace notar que el hombre que tiene, no es el hombre que es $y$, el hombre que es no puede reducirse a la consumación de los deseos. ${ }^{57}$

Las consecuencias para la ética se hacen sentir porque, en primer lugar, surge una nueva concepción de la felicidad porque ésta, para el cuarto hombre, es el placer que se experimenta en una determinada acción, y no es el ejercicio de una virtud particular y ni la libre praxis racional del hombre. El alcance de la felicidad no está en mí, sino en la exigencia perentoria de prestaciones que deben provenir de terceros y que se plantea en el dicho: "ustedes están obligados a hacerme feliz". Se reclaman, pues, las prestaciones de los otros y se piden de terceros, exigencias que me hagan feliz. ${ }^{58}$

En segundo lugar, surge un desencanto y desilusión, con sabor a fracaso, por el sentido de la felicidad política, que nace de una praxis racionalmente fundamenta- 
da e intersubjetivamente justificada en la comunicación personal y pública, y que en último análisis reclama una comunión en los valores humanos en el tomar en serio el bien común. ${ }^{59}$ Es necesario anotar que en la sociedad radical se alcanza la máxima privatización del concepto de felicidad: la unidad aristotélica del obrar virtuoso y de su alegría concomitante no significa nada, y, caída idea de misma de la felicidad política, queda solamente la búsqueda del placer privado. ${ }^{60}$

\subsection{El cuarto hombre es bueno por naturaleza}

Esta tendencia actual no tiene nada que ver con un optimismo en la naturaleza humana. Se trata de un naturalismo materialista que presenta tres maneras distintas de concebir la naturaleza pero que convergen en una nueva antropología en cuanto ignora toda "ley natural" y, en ella, "toda naturaleza humana" para llegar a afirmar que la persona puede ser manipulada, cambiada con los medios que ofrece la técnica. Lógicamente con el hombre se podrá realizar todo lo que es científicamente y técnicamente posible.

La crisis sobre la concepción de la naturaleza humana desemboca sobre la interpretación que se pueda dar a la humanidad de la persona y a sus derechos. Por ejemplo, los derechos humanos de la persona son más vistos como derechos de la naturaleza casi en igualdad con los animales y vegetales y, no como derechos que encuentran fundamento en la naturaleza humana. Entre las tres formas que presenta el naturalismo materialista hay ciertos matices que las diferencian y que convienen analizar:

El naturalismo que niega la existencia de un espíritu, de un alma espiritual. Distingue entre el cuerpo y la mente espiritual, pero interpreta a la mente espiritual como su sede en el cerebro y, por lo tanto, ésta desapare- 
cerá y morirá con la muerte del cerebro. Surge una mente sin trascendencia y sin espíritu e inclusive es expresión del cerebro.61 Así tenemos, por ejemplo, el "concordismo" exasperado entre las funciones cerebrales y las funciones espirituales, casi como si el espírtu quedaría amarrado a las solas funciones cerebrales; si es así ¿cómo podeos explicar el cariño más profundo de un niño "mongolito" que un niño cuyas funciones cerebrales son buenas y sanas?

El naturalismo que hace de la persona un ser más de la naturaleza y, por lo tanto, como un animal entre los otros, aunque se le reconoce un grado superior porque es más inteligente pero no diferente de los animales por naturaleza. De esta manera, se niega la trascendencia del hombre sobre los animales e inclusive a los animales se les reconoce los mismos derechos del hombre. Así tenemos, por ejemplo, que en algunos países se está por nombrar el Ministerio para los animales en el Ejecutivo, cuando no existe un Ministerio de la Mujer.

El naturalismo que atribuye una igualdad de naturaleza a todas las maneras de expresión sexual, para el cual la homosexualidad o la heterosexualidad son igualmente naturales. De ahí que, no se puede hablar de modos desviados de ejercitar la sexualidad, ni tampoco se puede hablar de modos antinaturales. Así tenemos, por ejemplo, la legalización de los matrimonios gays.

Este planteamiento naturalista, en pocas palabras, no es capaz de hacer una seria reflexión sobre lo que es humano en la naturaleza cayendo en una igualdad "natural" que achata al hombre en los límites de la naturaleza. Precisamente, es urgente poner en resalto lo "específicamente humano" si no queremos caer en una antropología meramente técnica o de tendencia animal. Las consecuencias sería irremediables para las actividades del hom- 
bre: ¿qué significa exigir "una política con rostro humano para el hombre de hoy? O, también podríamos llegar a afirmar que una economía sin rostro humano es perversa y salvaje. ${ }^{62}$

\subsection{El cuarto hombre se vincula por el contrato y no por la ley}

Las instituciones jurídicas fundamentales que regulan la convivencia social son dos: el contrato que es el consenso libremente intercambio entre las partes y que regula las relaciones interindividuales; $y$, la ley, que reglamenta las relaciones públicas-colectivas. El contrato que en las sociedades liberales "de entonces" regulaba sobretodo las relaciones patrimoniales, en las sociedad actual radical se extiende progresivamente a la valides de las relaciones ético-humanas, para intentar de poner remedio a la disolución de la vida social. ${ }^{63}$

El contrato poco a poco se va abriendo camino en la sociedad actual hasta convertirse en una forma jurídica que tiende a implantarse, teniendo en cuenta que si los individuos son tendencialmente asociales, solamente el contrato los puede tener sostenido y en conjunto. Invade, por tanto, todo el tejido de la vida social y pasa a formar parte de la vida diaria. El agravante radica en que el individuo postmoderno tiene dificultad excesiva en reconocer la superioridad del bien común sobre el bien individual que disfraza al egoísmo sin admitir derechos de justicia preexistentes a todo contrato. 64

Lo que vincula al contrato fuertemente es la reciprocidad, mientras que en la ley es la virtud del contenido de la racionalidad y de la voluntad, lo que le da un poder coactivo. Si cae la racionalidad de la ley y su orientación hacia el bien común y con ello el valor ético, enton- 
ces, la ley queda en el "limbo" de las abstracciones generales distanciada del verdadero significado de la existencia humana y, por consiguiente, sin calidad moral para favorecer el desarrollo humano de la persona. Queda reducida a la garantía de los intereses individuales y de los espacios libres individuales con la imposibilidad de garantizar la solidez social. El punto de llegada es la progresiva anulación de la dimensión pública y la reducción de lo político a lo privado, cuyos medios poderosos son la ampliación de los espacios extrainstitucionales regulados por el contrato y la dilatación de una concepción meramente convencional-contractual de la ley. En pocas palabras se impone el derecho privado sobre el derecho público, sin reglas claras en el "juego social”. Por ejemplo, el matrimonio que es de derecho público en cuanto es amparado por la ley, se convierte, en algunos casos, en simplemente en una conveniencia de un contrato privado recíproco, en una "pareja de hecho".

La filosofía del derecho y su producción en la sociedad postmoderna, es dominada por el "decisionismo jurídico", es decir, la atribución de la validez a un sistema legislativo solamente en virtud de su emanación de las instancias idóneas, lo que equivale a decir sustancialmente por la mayoría parlamentaria, la cual, a su vez, es aceleradamente cambiante según las conveniencias políticas del momento sin importarle "la ley justa" sino simplemente "la ley por conveniencia". Este decisionismo es consecuencia de un positivismo jurídico que considera a la ley no relacionada al derecho natural, sino como puro producto de la autoridad competente. De este modo, el voluntarismo jurídico se convierte en el principio fundamental del derecho radical y en la tentación clave de la sociedad actual. Si es así, el derecho se convierte en pura legalidad y son erradicadas todas las raíces éticas que sue- 
nan a "tradición" superada. Equivocadamente lo "ius" que indica lo justo y lo ético se identifica con la "lex" que posee solo valor formal y se constituye como resultado de una decisión, en último análisis contractual. ${ }^{65}$

Este sistema jurídico resulta precario y débil, no solamente porque está desenganchado del derecho natural sino también porque pierde referencia sustancial a la humanidad de la persona y conlleva a aprobar leyes, pero sin interés por preguntarse si sean "leyes justas". La certeza de la ley y la constancia del derecho son seriamente comprometidas ya que bajo su "paraguas" puede estar todo permitido y donde todo está permitido, nada está verdaderamente garantizado. Si a la base está el derecho de la fuerza, entonces es el hombre el que decide qué cosa sea derecho; así, por ejemplo, puede decidir cuándo la vida debe nacer si debe nacer y cuando la vida debe morir si debe morir. Es que, cuando falta en el ordenamiento jurídico un sustrato moral en la conciencia del hombre y del pueblo, se llega también a poner "en tela de juicio" el mismo derecho. ${ }^{66}$

\subsection{El cuarto hombre debilita la memoria histórica}

A la base de la concepción de la historia está la concepción que se tenga del tiempo. Ahora bien, la cultura radical se ha quedado con el tiempo presente $y$, ha dado la espalda al pasado rechazando la tradición y ha debilitado el futuro porque no interesa produciendo desilusión y una sensación de fracaso. En este marco de reflexión emerge la ausencia de la memoria histórica. La historia, por consiguiente, es considerada como "ciencia" pero pierde fuerza como memoria y como tradición viviente de una praxis del pasado que continúa en el presente. El problema que se origina es que si los hombres y los pueblos carecen de tradición y de memoria, están condenados a su fin. ${ }^{67}$ 
Surge, así, una mentalidad historicista en lo que interesa solamente es el presente y lo inmediato, cayendo en una especie de vértigo y vorágine del presente. La consecuencia lógica es el dominio de la angustia y de la desesperación que produce la enfermedad “de moda", el estrés. El hombre estresado y ansioso es un rasgo elemental de la actualidad. ${ }^{68}$ Se pierde orientación y sentido en la vida, originándose una libertad como libre expresión del hombre: el deseo y el propio querer.

Indudablemente que, cuando decae el sentido auténtico de la tradición, comienza el momento de la pobreza y del camino de la deshumanización. La tradición se convierte en puro y simple objeto de erudición. El hombre se sustrae de su patrimonio de memorias y de experiencias del pasado quedando siempre en eterno presente, a lo que venga porque viene. De esta manera, es comprensible la desconfianza que se tiene a ciertas instituciones del pasado porque son vistas como "anticuadas" y "pasadas de moda”. Por ejemplo, la Iglesia con sus 2000 años de historia es vista como institución anticuada y sus propuestas son tendencialmente marginadas. Todo ello exige, indiscutiblemente, una "puesta al día" en el lenguaje que utiliza y su forma de pensar debería responder a las nuevas instancias culturales. ${ }^{69}$

Resulta más que comprensible, también, la crítica a los valores tradicionales por la convicción profunda de que están relacionados con el pasado y, por tanto, son vistos como un mal. Y, es que la idea del progreso no solamente se aplica al desarrollo científico y técnico, sino también a toda la realidad humana, social y política, y, en ésta última, vale el principio de que "todo lo nuevo es mejor y superior" y, oponerse a éste es señal de oscurantismo y atraso para la humanidad. ${ }^{70}$ El "snobismo" -la novedad por la novedad- se convierte en criterio orientador para la convivencia humana. 


\section{Conclusión}

El surgimiento y la afirmación del "cuarto hombre" representan un enorme desafío para la educación actual. Pretender ignorar esta emergencia antropológica es "pretender tapar el sol con un dedo". La educación debe asumir este desafío sin miedo y sin temores, tanto más, que el hombre -su desarrollo humano- constituye el centro del hecho educativo y la razón de ser de su misión. La reflexión que hemos realizado nos ofrece las pautas para platear un camino educativo en la cultura radical.

Urge, por consiguiente, una orientación que acentúe las preguntas claves de la existencia humana: el sentido de la vida humana, el significado de la existencia, el misterio de la muerte ante el sincretismo actual, la orientación de la libertad humana, la presencia de Dios en lo humano y como humanizante del hombre: es como un renacer a lo que es fundamental en la vida humana. ${ }^{71}$ Esto que es "fundamental" es la tarea que la educación debe saber afrontar y esgrimir, y, no perderse en cuestiones secundarias que la distraen de su misión esencial. Por un lado, debe asumir estas preguntas que surgen del "cuarto hombre" $y$, por otro lado, debe lanzar propuestas abiertas que las asuman.

Considero que, esta reflexión, asumida por la filosofía de la educación debe acentuar lo "específicamente humano" en la naturaleza y en el mundo para superar las dicotomías y establecer líneas operativas que resalten: la fuerza humanizante de la ética, la capacidad de hacerse cultura de la fe, la riqueza de la cultura intercultural emergente y la unidad del hombre en una ontología espiritual en la que el hombre espiritualiza y eleva toda la naturaleza pero sin mezclarse y confundirse. Desde esta óptica, emergerán los límites discutibles del "cuarto hombre". 
Notas:

1 Cf. NIEZSCHE, F., Así habló Zaratustra, Buenos Aires 1967, pp. 45-75.

2 El alcance de estos desafíos los afronta en mi reciente obra Nueva Educación (Quito 2006), sobre todo, pp. 14-78.

3 En estricto sentido es una definición sujetada a la rigidez de la lógica y, por tanto, muy limitante para entender al hombre. El cuadro es preciso: "animal" es el género próximo y "racional" es la diferencia específica.

4 Cf BOECIO, M.S., La consolación de la filosofía, México 1978, pp. 34-56.

5 Cf. MOUNIER, M., La revolución humanista, Buenos Aires 1980, pp. 34-89., Mounier, Marcel, Buber y Wojtila insisten también en el otro versante de la persona como "ser en relación", sin ignorar este versante ontológico.

6 Aristóteles, consejero del Emperador Alejandro Magno, justificaba la esclavitud que el emperador realizaba en las tierras conquistadas.

7 La revelación como manifestación progresiva de Dios al hombre llega a su culmen con Jesucristo que es la misma revelación divina.

8 No estamos, pues, de acuerdo con ciertas tesis que afirman "a secas" la helenización del Evangelio", pues, el mundo helénico no llegó a alcanzar algunos temas que, sin el aporte del Evangelio hubiesen resultado imposibles. Bástenos constatar en el amor la diferencia entre el "eros" griego y el "ágape" cristiano. Cf. BENEDICTO XVI, Deus est charitas, Roma 2005, ns. 6-11.

9 Quizás con Santo Tomás de Aquino se alcanza la cumbre de esta reflexión. Podemos ver, su obra Compendio de Teología, México 1987.

10 Cf. DESCARTES, R., El discurso del método, Lima 1990, pp. 3-9. Desde esta óptica las cuestiones de fe se divorcian de las cuestiones de la razón. Véase JUAN PABLO II., Fides et ratio, Roma 1994, ns.3-7.

11 Cf. SIEROTOWICZ, T., L'uomo postmoderno e la sua cultura, en el Nuovo Aeropago 15 (1996) 13-17. Para entender el postmoderno, el autor hace un estupendo análisis del moderno

12 En el siglo XIX surgen universidades cuyo lema es "el bienestar proviene de la ciencia”. Nada más discutible e ingenuo. 
13 La fuerza del positivismo radica en la plena satisfacción del conocimiento científico para el hombre. Así, Comte afirmará la superación toral del estadio metafísico y del estadio religioso.

14 Este "aufhebung" es clave para entender toda la dialéctica hegeliana en la cual el "saber absoluto" es la máxima realización del pensamiento, destruyendo y superando el "saber del arte" y el "saber de la religión”. Cf. Hegel, F., Lógica, Buenos Aires 1967.

15 Cf. KIERKEGAARD, S., Diario, Lima 1987.

16 Cf. SAAVEDRA, A., Nueva Educación, pp. 113-145.

17 Cf. CICCHESE, G., Il quarto uomo: Postmoderno o crisi della modernitá, en Nuova Umanita 20 (1998), pp. 192-213.

18 Cf GEHLEN A., Die Säkularisierung des Fortschritts (Frankfurt 1999) 403-412.

19 Cf. FREUND, J., Geschehen ohne Geschichte, en Der Horizont 9 (1966), pp. 15-31.

20 Cf. HELLER, A., Per cambiare la vita, Roma 1980.

21 Es lo que Kant preconozaba en su Crítica del juicio, Buenos Aires 1978, pp. 23-56. Podemos decir que entramos en la "crisis de fines" con la superproducción de medios.

22 Cf. MCLUHAN, M., La Galassia Gutenberg, Roma 1976. Afirma que hemos pasado de la galaxia Gutenberg (tercer hombre) a la galaxia telemática (cuarto hombre). Puede verse, también del mismo autor Los instrumentos de la comunicación, Lima 1989, pp. 34-56.

23 Cf. ADORNO, Th., Minima moralia, Torino 1954, pp. 112-114. Por otra parte W. Benjamín hablaba de una "recepción en la distracción" Puede verse en su obra, Gli strumenti del comunicare, Milano 1967,

24 Cf. SAAVEDRA, A., Formación de la conciencia en valores, Quito 2005, 3ra ed., pp. 34-56.

25 Marcel rechazaba la afirmación de que el hombre no se compromete y, afirmaba, más bien, que el hombre actual sí se compromete pero con lo efímero. Cf. Del rechazo a la invocación, Buenos Aires 1978, p. 34.

26 Es la mentalidad historicista que se impone en el devenir de la historia, surgiendo un descrédito por la misma. Cf. FUKUYAMA, F., El fin de la historia, Santiago 1997.

27 Cf. MORRA, G., Il quarto uomo. Postmodernitá o crisi della modernitá?, Roma 1996, pp. 98-99.

28 Cf. SAAVEDRA, A., Nueva Eduación, pp. 110-123. 
29 Cf. PRANDSTRALLER, G., L'uomo senza certezze e le sue qualitá (Trad. El hombre sin certezas y sus cualidades), Roma 1992, pp. 20-23.

30 Será muy positivo recordar el aporte de E. Mounier en su obra Revolución humanista, México 1978, para poder identificar la confrontación entre individuo y persona.

31 Cf. BOTTURI, F., Desiderio e veritá. Per una antropología cristiana nell'etá secolarizzata (Trad. Deseo y verdad. Por una antropología cristiana en la edad secularizada), Milán 1985, pp. 50-56.

32 CF. TOMÁS DE AQUINO, In IV Sententiarum, d.2,q.1,a.1., puede verse también BOECIO, M., Commentarium in Porphyrium III, en PL 64,114.115.

33 Cf. NIETZSCHE, F., Así habló Zaratustra, pp. 67-69.

34 Jean Galot ha profundizando estupendamente el concepto de persona en la formulación del dogma de la Trinidad (Concilio de Nicea 325), afirmando que la relacionalidad de las personas divinas en el concepto de "hispótasis" (=persona) es inédito en la historia del pensamiento. Puede verse, GALOT J., Gesú, chi é? (Roma 1980) pp. 134-201. Es un dato teológico que no se puede prescindir en el devenir histórico del concepto de persona.

35 Cf. WOJTILA, K., Persona y acción, Madrid 1980, pp. 34-56.

36 Cf. idíb., pp. 67-89.

37 Son numerosos los pensadores contemporáneos que propugnan este claro "traspaso" y que no se pueden soslayar por su valiosísimo aporte a la búsqueda de humanización del hombre actual, entre los que destcana: Buber, Marcel, Mounier, Nédondellle, Wojtila y Scheler.

38 Las distintas formas de naturalismo materialista actual las afrontamos en nuestro estudio Nueva Educación, pp. 45-50

39 Cf. BEJAR, H., El ámbito íntimo. Privacidad, individualismo y modernidad, Madrid 1988, pp. 34-56.112-114; BERGER B.-BERGER P., The war over the family, New York 1983.

40 Cf. STIRNER, M., L'Unico e la sua proprietá (Trad. El Unico y su propiedad), Milán 2000.

41 Se trata de un individualismo anárquico que no acepta ideales, ni deberes, ni vocaciones, ni valores, ni verdad, ni autoridad. El único mandamiento que puede ser aceptado es: "Yo me levanto sobre mí mismo sobre toda verdad”. Cf ibíd., pp. 345-348.

42 Cf. BRUNI, G., Dire Dio agli uomini d'oggi. Línee di discussione (Trad. Hablar de Dios al hombre de Dios. Líenas de discusión), en POUPARD P (ed.), Parlare di Dio all'uomo postmoderno, Roma 1994, pp. 20-25. 
43 Co POSSENTI V., La cultura radicale, en IDEM, Filosofia e societá (Trad (Filosofía y sociedad), Milásn 1983, pp. 110-112.

44 El amor como donación a la luz del Evangelio es riqueza para el que se dona. Cf. BENEDICTO XVI, Deus est charitas, Roma 2005, ns 6-8.

45 Se proyecta más un "consenso de conveniencia" o un "consenso circunstancial político" y, no un "consenso humano" que se fundamento en torno al valor de la persona humana.

46 Visión clara y determinante en Aristóteles que considera la Ética de la virtud y de la felicidad. Cf. Ética a Nicómaco, México 1978, passim.

47 La urgencia de esta reflexión antropológica es insustituible para Wojtila. Cf. WOJTILA, K., Antropología cristiana (Lima 1988) 23 56. Mi estudio, Fundamentación metafísica de la dignidad de la persona humana. Actas del IX Congreso Internacional de Filosofía, Roma 1990, vol. III, pp. 123-145.

48 Cf. FRANKL, V., El hombre en busca de sentido, Buenos Aires 1994, pp. 23-56.

49 Cf. McYNTIRE, A., Dopo la virtú (Trad. Después de la virtud), Milán 1981. Estupenda investigación del filósofo escocés sobre la crítica aguda al universalismo ideológico de la moral moderna y sus respectivas colocaciones históricas. Fundamentar racionalmente una moral, lejos de las abstracciones iluministas y del nihilismo de sello nietzscheano.

50 Cf. ibíd., 34-67.

51 Cf. FRANKL, V., op. cit., pp. 20-24. Mi libro Nueva educación, pp. 36-45, plantea precisamente esta visión limitada del hombre.

52 Cf. STIRNER, M., op. cit., p. 247.

53 Cf. MARCUSE H., Eros y civilización, Madrid 1968, pp. 150-155.

54 El ser es esencialmente lucha por el placer. Esta lucha se convierte en una meta de la existencia humana porque concede alegría, felicidad libertad y comunión. Cf. ibíd., pp. 156-158.

55 Podemos decir que la necesidad se cambiado por la "elección de los deseos en cuanto son inventados y recreados continuamente" Cf SAAVEDRA A., Nueva Educación, pp. 123-134.

56 Cf. ibíd., pp. 140-142.

57 Es que el hombre tiene, el hombre económico, pretende ser la base de la dilatación de los deseos porque pretende no solamente consumir los deseos sino también pagarlos a toda costa. Cf. SEN, A., Lo sviluppo e la libertá (Trad. El desarrollo y la libertad), Mi- 
lán 2000, passim. En esta línea LUTTWAK, E., La dittatura del capitalismo. Dove ci porteranno il liberalismo selvaggio e gli eccessi della globalizzazione (Trad. La dictadura del capitalismo. A dónde nos llevarán el liberalismo salvaje y los excesos de la globalización, Milán 1999.

58 Desaparece la exigencia personal y entra a tallar las exigencias que pido a los demás. Cf. POSSENTI, V., La cultura radicale (Trad La cultura radical), Milán 1983, pp. 94-96.

59 Cf. JUAN PABLO II., Centessimus Annus, Roma 1991, ns. 34.39.

60 Cf. McYNTIRE, A., Dopo le virtú, pp. 120-145.

61 Debemos hablar de una mente espiritual o inteligencia espiritual que supera la simple materialidad de las cosas para comprenderlas y elevarlas. La fuerza espiritual de la inteligencia le permite al hombre dignificar el cosmos como una misión estrictamente humana. Cf. BUNGE, M., Mente y cerebro, Lima 1993, pp. 45-89.

62 Si no reflexionamos sobre estas famosas frases que se repiten en diferentes foros o encuentros internacionales: "dar un rostro humano a la economía", "dar un rostro humano a la globalización", etc, no tendría ningún sentido lo que el Grupo de los 8 afirmaba al respecto en junio de 2000

63 Cf. POSSENTI, V., op. cit., p. 122.

64 El contrato se convierte en algo convencional y, en algunos casos en derecho de la fuerza y del poder.

65 Pasamos a la "conveniencia" del momento, la cual, puede ser cambiada por otra conveniencia si importar las contradicciones y los atropellos que se puedan dar a lo "justo". Puede verse, SAAVEDRA A., Nueva Educación, pp. 56-67; ÍDEM., Lo politico en la Doctrina Social de la Iglesia, Lima 1988, pp. 67-70.

66 Cf. PANNENBERG, W., Fondamenti dell'etica.Prospettive filosofico.teologiche (Trad. Fundamento de la ética. Prospectivas filosófico. teológicas, Milán 1989, pp. 23-31.

67 Cf. FUKUYAMA, F., El fin de la historia, Barcelona 1990.

68 Se puede entrever en Sartre cuando afirma que la vida es una náusea. Cf. SARTRE, J.P., La náusea, Buenos Aires 1978, pp. 45-78.

69 Es urgente asumir sin ambajes las nuevas "claves de interpretación" para comprender al hombre que surge de esta mentalidad, si no queremos mantener la educación totalmente al margen de la historia.

70 En el fondo es una mentalidad neopositivista radical que confía más en lo último para el bien de la humanidad y no en lo anterior. 
71 Los aportes valiosos de psicólogos como Víctor Frankl y Carl Rogers; de filósofos personalistas como Manuel Mounier, Gabriel Marcel, Karol Wojtila y Martín Buber, resulta fundamentales para la educación actual. 